\title{
Verbal discrimination learning and retention as a function of performance or observation and ease of conceptualization of task materials
}

\author{
MELVIN H. MARX, KATHLEEN MARX, and ANDREW L. HOMER \\ University of Missouri, Columbia, Missouri 65201
}

\begin{abstract}
Four classes of high school psychology students were given verbal discrimination learning tasks with correct responses of varying ease of conceptualization. Study trials were administered with subjects working in pairs, with each subject alternately performing (selecting one of the two projected words) and observing (watching partner make selection). Both in acquisition and in 24-h free recall tests, more correct responses were made under the performance condition. Also, in each instance, there was a reliable Perform/Observe by Group (task) interaction. These results are interpreted as offering support for the proposition that reward functions, presumably operating more directly in the perform than in the observe condition, have some strengthening effect on responses that cannot be accounted for in terms of strictly cognitive processes.
\end{abstract}

This experiment continues the analysis of verbal discrimination learning as a function of task initiated in a recent experiment (Marx, Homer, \& Marx, 1980). In the earlier experiment, three tasks were used, with correct answers determined (1) by a simple conceptual rule (always the shortest word), (2) by the fitting together of successive correct words into meaningful phrases, and (3) randomly. In acquisition, performing subjects (who selected their own responses) were slightly inferior on the conceptual task and slightly superior on the rote task (randomly determined correct words) when compared with observing subjects (who received equivalent information by watching paired performers respond). However, this interaction was only of marginal statistical reliability and could not be interpreted as providing much support for the proposition that performance would operate more effectively, presumably by means of some kind of strengthening from reward, on the simpler rote materials, whereas the cognitive processes presumably more active in observation would result in more effective learning of the conceptual task.

The present experiment was designed to provide a more systematic manipulation of the task variable. One,

This work was supported in part by a research career award from the National Institute of Mental Health and a grant from the Army Research Institute for Behavioral and Social Sciences, both to the first author. The opinions expressed herein are those of the authors alone and do not constitute endorsement by the U.S. Army. We thank Joan Girnis and Gary Blodick, psychology teachers at Naples High School, Naples, Florida, for their cooperation in providing participants for this study and making it a part of their instructional program. This research was conducted in accordance with university regulations governing rights of participants. Following the completion of data collection, the main parts of the experimental design were discussed and the students were invited to ask questions about psychology as a college major and a career. two, or three conceptual categories were involved in the determination of correct responses in each set of 12 word pairs. A fourth, control, condition had randomly determined correct responses. Otherwise experimental conditions were essentially similar to the previous study (Marx et al., 1980).

\section{METHOD}

\section{Design}

The four levels of the ease-of-conceptualization variable, with one high school class given each level, were as follows: Group R (random correct answers), Group 3C (three concepts for correct answers), Group 2C (two concepts for correct answers), and Group 1C (one concept for correct answers). The perform/observe variable was manipulated within subjects by providing alternate roles for pairs of subjects.

Subjects

Participants were four high school psychology classes, tested in their usual setting (class sizes of $22,36,22$, and 20 ).

\section{Procedure}

Students were placed in like-sex pairs as they entered the classroom. The person on the left. of each pair served first as a performer (for first set of 12 word items) and then as an observer (for second set of 12 items). The correct words in each word pair were drawn from the pools of categories provided by Battig and Montague (1969); negative instances were randomly drawn from multiple categories (no more than two in a list from any one category).

Subjects were told that they were to guess, as performers, which word in each pair was correct on the first trial. The two words were projected on slides, and performers circled the number 1 or 2 , indicating their choice of words. The correct answer was given orally by one of the experimenters after all of the performers had responded (at the 5-sec point of the 8-sec automatic presentation schedule). At the conclusion of the 12th pair, subjects changed roles and the second set of 12 word pairs was presented. In each case, this list was of the same structural type as the first list but differed in concepts and specific words (e.g., all of the correct words were spices in one 
of the lists for Group 1C and diseases in the other list; all of the correct words for the categories used in the other groups were fruits, relatives, snakes, and distance measures for $2 \mathrm{C}$, and flowers, metals, footwear, occupations, government employees, and cooking utensils for $3 \mathrm{C}$ ).

Immediately after each study trial, with correct answers provided, an interpolated test trial was administered, in order to assess observer as well as performer acquisition, with subjects working individually and with no further information provided. A 5-sec slide-presentation rate was used for this trial. Four pairs of study-test trials were administered to each class.

Observers were instructed to note the responses of their paired performers, as well as the correct answers. Both performers and observers were cautioned that they would be tested on all of the word pairs regularly.

On the day immediately following the five paired acquisition trials, all of the subjects were asked to write down as many of the correct words as they could remember in a 2-min free recall test administered in the usual classroom setting.

\section{RESULTS}

As was to be expected, statistically reliable group and trial differences occurred in acquisition. Mean correct responses were 8.3, 8.2, 9.3, and 11.4 for Groups $\mathrm{R}$, $3 \mathrm{C}, 2 \mathrm{C}$, and $1 \mathrm{C}$, respectively $[\mathrm{F}(3,92)=26.36, \mathrm{p}<.01]$. Newman-Keuls specific comparison tests indicated that Group 1C was reliably different from all of the others and Group $2 \mathrm{C}$ was reliably different from Groups $3 \mathrm{C}$ and $\mathrm{R}$, both at the .01 level of confidence. Test trial means were $7.8,8.5,9.7$, and 10.4 from the first to the fourth trial $[F(3,276)=49.50, p<.01]$.

The perform/observe variable also produced a reliable overall difference, 9.2 mean correct responses for performance and 8.8 for observation $[\mathrm{F}(1,92)=68.51$, $\mathrm{p}<.01]$. Of greater interest, however, is the reliable interaction between performance and group variables $[F(3,92)=8.52, p<.01]$. This interaction is plotted in Figure 1.

One other reliable interaction in acquisition is of interest. Sex of subjects interacted with trials $[F(3,276)$ $=2.64, p<.05]$. Female subjects started at the same level as males but were superior by the fourth trial (female means of $7.8,8.5,10.1$, and 10.7 for Trials 14 , respectively; corresponding male means were $7.8,8.5$, 9.3, and 10.0).

The 24-h free recall data showed a reliable group effect for correct responses recalled $[\mathrm{F}(3,92)=23.89$, $\mathrm{p}<.01]$; Group R had a mean score of 2.75; Group 3C, 3.99; Group 2C, 6.07; and Group 1C, 6.03. No other effects or interactions were reliable.

Male subjects made twice as many erroneous recalls as did female subjects (means of .63 and .30$)[F(1,92)=$ $4.59, \mathrm{p}<.05]$. There was also a reliable group effect for this measure $[\mathrm{F}(3,92)=5.09, \mathrm{p}<.01]$, with regularly increasing error scores from Group $1 \mathrm{C}$ to Group $\mathrm{R}$ $(.03, .11, .29$, and .43 , respectively).

\section{DISCUSSION}

The results of this experiment provide much better support than the previous similar but less systematically designed study (Marx et al., 1980) for the hypothesis that the reward process

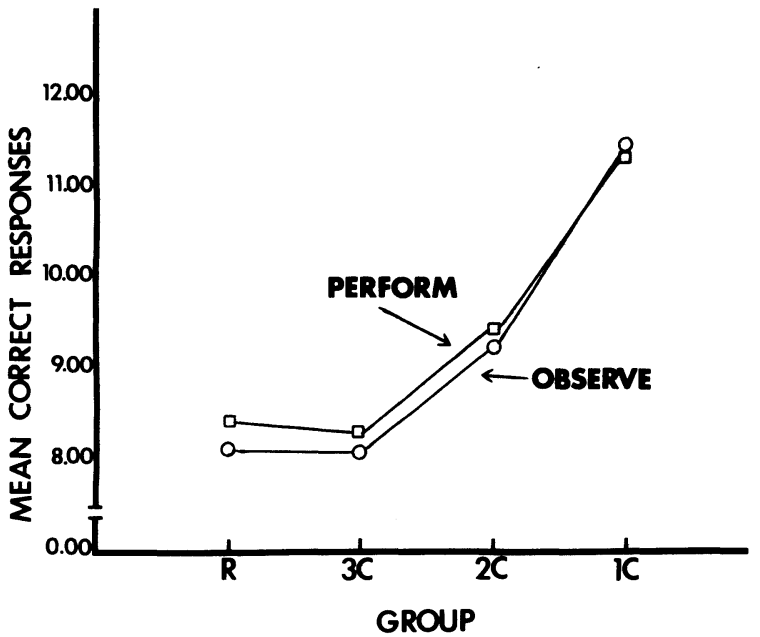

Figure 1. Mean number of correct responses in acquisition under performance and observation as a function of the task variable.

presumably more directly involved in acquisition of performed responses acts to strengthen such responses more than the cognitive processes involved in acquisition of observed responses. The supporting evidence comes not only from the reliably greater mean number of performed responses acquired, but also, and more strongly, from the interaction of perform/observe and task variables. The fact that the simpler rote memory functions (Groups $R$ and $3 \mathrm{C}$ ) were apparently more affected by the perform operation, as shown in Figure 1, is consistent with any theoretical interpretation that focuses on the fundamental role, if not the automaticity, of such functions; this kind of process would be freer to operate, and to operate without interference, in rote tasks than in the more cognitively demanding tasks in which conceptualization is involved. The performer superiority is all the more impressive not only because observers have more time to rehearse (not being required to make response decisions), but also, and more important, because they have been shown to concentrate on rehearsing the correct responses in binary discrimination learning tasks (Eelen \& d'Ydewalle, 1976).

A similar interpretation has been recently advanced to account for superiority of performance in certain phases of a transfer experiment (Marx, 1980).

The interaction between sex of subject and trials indicates the usual female superiority in verbal acquisition, in this case a delayed effect. The tendency of males to make more erroneous recalls is another expression in these data of this commonly reported sex difference.

\section{REFERENCES}

Battig, W. F., \& Montague, W. E. Category norms for verbal items in 56 categories: A replication and extension of the Connecticut category norms. Journal of Experimental Psychology Monograph, 1969, 80, 1-45.

Eelen, P., \& D'Ydew Alle, G. Producing or observing responseoutcome contingencies in a two response alternative task. Psychologica Belgica, 1976, 16, 61-71.

MarX, M. H. Multiple-choice learning of line-drawn facial features: III. Transfer as a function of performance or observation. Bulletin of the Psychonomic Society, 1980, 15, 57-59.

Marx, M. H., Homer, A. L., \& Marx, K. Verbai discrinuination learning and retention as a function of task and performance or observation. Bulletin of the Psychonomic Society, 1980, 15, 167-170.

(Received for publication June 21, 1980.) 